\title{
STRONG LEADERSHIP AND POLITICAL WILL IN \\ FRAUD AVOIDANCE
}

\author{
Safril Hidayat \\ safrilhidayatzeni1995@yahoo.co.id
}

\author{
Article history: \\ Received July 31, 2016 \\ Revised Dec 23, 2016 \\ Accepted May 20,17

\section{JEL Classifications} \\ D72; D73; H39

\section{Key Words: \\ Leadership; \\ Political will; \\ Decentralization; \\ Law enforcement; \\ Self-consciousness}

ARTICLE INFORMATION

\section{DOI:}

10.21532/apfj.001.17.02.01.08

\begin{abstract}
Post reformation, Indonesia emerging as a democratic state. On one side, democracy bringing new chapter in political life, but on the other euphoria of democracy excessively rising. Openness brings negative impacts such as fraud in the financial sector, company that carried out by individual or organized group of people. Government of Indonesia established Indonesia's Financial Services Authority (OJK). Fraud does not only happen in Indonesia. In many parts of the world fraud occurs and involves politics. It can be seen that the actors who commit fraud come from different back ground and social status. Todays, fraud form of action can be diversed and sophisticated as well as development of modern technology, new regulations, and systems. This research uses a qualitative research design. Analyses were performed by literature review. Thus fraud is fraudulent acts, performed in such a way that benefits yourself / group to harm others (individuals, companies or institutions). Encouragement that helped prompt fraud are as follows: pressure (the urge to commit fraud), opportunities (opportunities that enable fraud), and rationalization (perpetrator to justify his actions). Overall encouragement of fraud is known as the fraud triangle.Based on fraud triangle, the simplest way to avoid fraud by high selfconsciuosness, strong political will and law enforecement, and leadership and decentralization
\end{abstract}

\section{Introduction}

Post reformation, Indonesia emerging as a democratic state. On one side, democracy bringing new chapter in political life, but on the other euphoria of democracy excessively rising. Openness brings negative impacts such as fraud in the financial sector, company that carried out by individual or organized group of people. Government of Indonesia established Indonesia's Financial Services Authority (OJK), the central government's agency that regulates and supervises Indonesia's financial services 
Safril Hidayat : Strong leadership and political will in fraud avoidance .....

Page 81-92

sector, needs to hire hundreds of new staff in order to safeguard monitoring of the nation's banking sector and to enhance its early warning system in order to detect possible corruption cases. As up to 350 OJK workers are expected to return to the central bank per 1 January 2017, good monitoring of the banking sector is in jeopardy. Based on the fact that in 2008-2014 there are some big cases of fraud occured are as follows:

Table 1. Fraud recapitulation in 2008-2014

\begin{tabular}{|c|l|l|l|}
\hline No & \multicolumn{1}{|c|}{ Case } & \multicolumn{1}{c|}{ Total Loss } & \multicolumn{1}{c|}{ Actors } \\
\hline 1 & Bank Century Scandal (2008) & $\begin{array}{l}\text { \$573 million bailout } \\
\text { package }\end{array}$ & Official Government \\
\hline 2 & Bank Syariah Mandiri Scandal (2013) & IDR 102 billion & Bank Employees \\
\hline 3 & Citibank Indonesia Scandal (2012) & \$3 million & Citibank Manager \\
\hline 4 & Bank Mega Scandal (2011) & \$8 million & Elnusa Company \\
\hline 5 & CIMB Niaga Scandal (2014) & IDR 22.9 billion & $\begin{array}{l}\text { staff-member at the } \\
\text { Information Technology } \\
\text { department }\end{array}$ \\
\hline
\end{tabular}

(Source: http://www.indonesia-investments.com/id/finance/financial-columns/banking-sectorindonesia-ojk-needs-more-people-to-combat-fraud/item6351. Downloaded on 5 July 2016, 14.03).

Fraud does not only happen in Indonesia. In many parts of the world fraud occurs and involves politics. In some cases, fraud actors supported government in power. Fraud also occurs in developed countries, as outlined in Table 2 below:

Table 2. Fraud Around the World

\begin{tabular}{|c|l|l|}
\hline No & \multicolumn{1}{|c|}{ Case } & \multicolumn{1}{|c|}{ Total Loss } \\
\hline 1 & The Sale of the Roman Empire (193 A.D.) & \\
\hline 2 & The Mississippi Scheme (1719) & \\
\hline 3 & The Diamond Necklace Hoax (1785) & Triggered the French Revolution \\
\hline 4 & The Wright Panic (1900) & Wealthy of lords and ladies \\
\hline 5 & The Original Ponzi Scheme (1920) & Over \$10 million \\
\hline 6 & The Eiffel Tower Sale (1925) & Over \$200,000 \\
\hline 7 & The Match King Hoax (1929) & Over \$500,000 \\
\hline 8 & The Baker Estate Swindle (1936) & \$25 million \\
\hline 9 & ZZZZ Best Cleaners (1986) & \$264 million \\
\hline 10 & The Great Insider Trading Scam (1986) & \$100 million \\
\hline 11 & The Savings \& Loan Scandal (1989) & \\
\hline 12 & The Enron Bankruptcy (2001) & \$101 billion \\
\hline 13 & The Madoff Pyramid (2008) & \$18 billion \\
\hline 14 & The Great Wall Street Rip-Off (Ongoing) & \\
\hline
\end{tabular}

(Source: http://www.cbsnews.com/media/top-14-financial-frauds-of-all-time, dowloaded on 5 July 2016. 13.07) 
It can be seen that the actors who commit fraud come from different back ground and social status. While not intending to generalize but can be seen that the perpetrator could be anyone in the field of employment. But certainly the culprit is the human individual or roup of people to commit fraud against other people or organizations that cause lost. Todays, fraud form of action can be diversed and sophisticated as well as development of modern technology, new regulations, and systems.

There are two kinds of mistake in financial sector which is errors and fraud. The difference between error and fraud are separated by a thin membrane which is known as intentional factor. In many cases, it is difficult to identify fraud because of the tendency of individuals or organizations to hide it. Thus fraud is fraudulent acts, performed in such a way that benefits yourself / group to harm others (individuals, companies or institutions). Encouragement that helped prompt fraud are as follows: pressure (the urge to commit fraud), opportunities (opportunities that enable fraud), and rationalization (perpetrator to justify his actions). Overall encouragement of fraud is known as the fraud triangle.

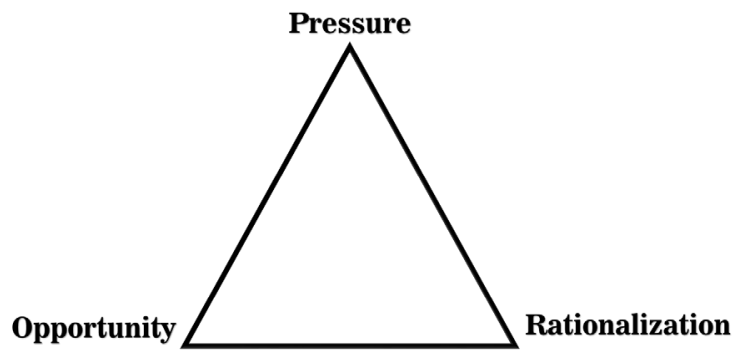

Figure 1. Fraud Triangle
Fraud based on perpetrators is consisted of employee fraud (fraud on an individual basis) and management fraud (fraud committed by management). Fraud is committed by unscrupulous rogue done to deceive stakeholders of organization.

Association of Certified Fraud Examiners (ACFE) divides two types of fraud are such as Asset Misappropriation consisting of cash and non-cash Misappropriation Misappropriation; Fraud Against Financial Statements (Fraudulent Statements), which consists of financial and non-financial.

The phenomenons of fraud are attracting me in researching on fraud and efforts to avoid it. In this article the authors premise is weaker system and lack of political will developing bigger chance of fraud opportunities.

\section{Methodology}

This research uses a qualitative research design. Analyses were performed by literature review. Primary data were obtained through analysis of views and arguments of national leaders and anti-corruption agencies, the financial services authority, and law enforcement. Secondary data obtained through books, articles, and both printed and online media.

\section{Conceptual Framework.}

What is Fraud? There are so many definitions of fraud. According to Black's Law Dictionary fraud is "covering all kinds of conceivable human, and pursued by a person, for the benefit of another person with the wrong suggestion 
or coercion truth, and include all unpredictable ways, full of violent tactics, hidden and any dishonest ways that cause others to be fooled. In short it can be said that fraud is cheating of money or properties.The Institute of Internal Auditor (IIA) determines fraud as "An array of irregularities and illegal acts characterized by intentional deception".

Webster's New World Dictionary defines fraud as a form of deception for personal purpose. Internationa Standards of Auditing section 240 - The Auditor's Responsibility to Consider Fraud in an Audit of Financial Statement paragraph 6 defines fraud as "...intentional acts by members of the company management, the parties involved in governance, companies, employees, or third parties who commit deception or fraud to gain an unfair or illegal". CGMA defines "Fraud essentially involves using deception to make a personal gain dishonestly for oneself and/or create a loss for another." Thus the motivational factor can be the same, enriching himself / group and the same modus operandi, is to perform in ways that are illegal. Based on fraud triangle, the simplest way to avoid fraud by high self-consciuosness, strong political will and law enforecement, and leadership and decentralization as mentioned by figure 2 below:

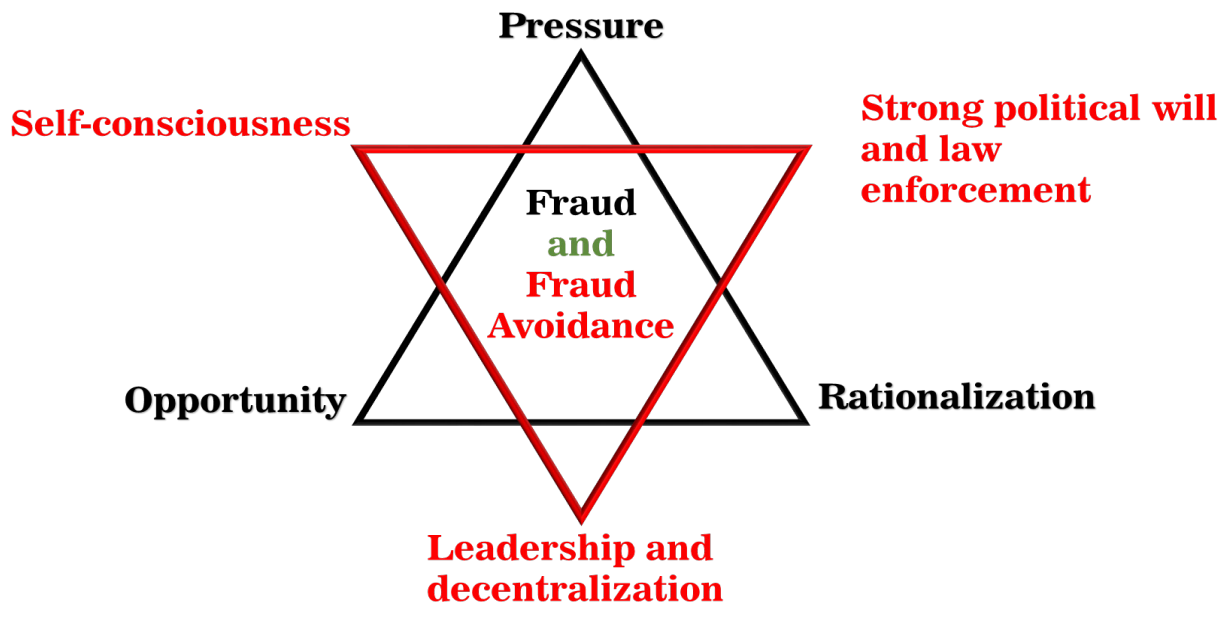

Figure 2. Conceptual framework

\subsection{Self-consciousness.}

Throughout our waking life, we are conscious of a variety of things. We are often conscious of other things. Sometimes we are also conscious of ourselves, our features, and the events that take place within us. Thus, we may become conscious, in a certain situation, of the fact that we are nervous or uncomfortable.
Thus William James (1961:42) remarked once that "whatever I may be thinking of, I am always at the same time more or less aware of myself, of my personal existence". Selfconsciousness has thus mostly focused on the identification and articulation of epistemic and semantic peculiarities, that is, peculiarities as regards how we know, and more generally how we represent, ourselves and our internal lives. 
Perhaps the best known philosophical threat to the very possibility of self-consciousness hails from Hume's (1739) remarks in the Treatise of Human Nature (I, IV, VI): "For my part, when I enter most intimately into what I call myself, I always stumble on some particular perception or other... I never can catch myself without a perception, and never can observe anything but the perception." According to those theories, perception can represent what we know. Therefor, understanding the basic value of social culture and ethics can be applicable to avoid fraud in the daily life.

\subsection{Strong political will and law enforcement.}

In discussing governance reform efforts that have not worked, the phrase 'political will' comes up a lot, usually in the formulation 'lack of political will'. But it appears that the phrase is so elastic it is becoming meaningless. 'Political will' tends to mean this: we got the government to agree to a program of reform, either to accept a grant or take a loan designed to pay for the program. Lori Post et al (2008:114) in Odugbemi and Jacobson (2008) ., 'political will can be thought of as support from political leaders that results in policy change' as well as Matthew Andrews (2004, 2007:105) and Odugbemi and Jacobson (2008), says the real solution is 'political engagement that focuses on expanding space for change... .

Strong political will is formed through a strong personal awareness. Strong political will would result in effective regulation in enforcing the law. Effective regulatory is consisted of indicators to determine fraud. These indicators are wrapped in the form of regulatory law. Socialization of law ang regulations will generate curiousity and awareness to the organization or individual.

Law enforcement is the activity of making certain that the laws of an area are obeyed. Law enforcement not only by governments, but also involving the company or organization. The government makes regulations that restrict the behavior of fraud, and the legal apparatus consistency to enforce it.

\subsection{Strong Leadership and decentralization.}

Most leadership is by example, and the effect of example can be very enduring. Great leadership influence the lives of all those you influenced, mentored, encouraged and taught. In this case leading by example that does not tolerate any kind, forms, and modus of fraud. All strong leaders know their own strengths and weaknesses. They know their limitations, and what complementary skills they need in their teams to work most effectively. They are humble, teachable and quick to defer. What is more, they listen to the voice within, to their own thoughts and values about what really matters. They are sensitive to their own conscience as a higher principle, and use this guide as a check against every action they may be about to take, even where it appears to be permissible in law and acceptable generally.

On the other hand, "decentralization" generally means the devolution of decisionmaking powers. A related concept is 
"deconcentration," in which operations are decentralized, but decision-making powers are not devolved. Decentralization is in which lower level autonomy to set their own priorities and decide how best deliver public services. In addition, decentralization does not necessarily denote an erosion of central control nor of powers over issues and processes with national dimensions. But decentralization is not an automatic remedy. The dangers of decentralization have been listed by many, and include a lack of capacity causing macro instability (Prud'homme,1994; Tanzi,1995;1995b). Others have tracked the diversion of funds in decentralized settings (Reinikka and Svensson, 2004) while still others have warned of the dangers of capture by local elites (Bardhan and Mookherjee, 2000).

Companies and organizations have internal auditors or supervisors. Both sectors are crucial. If two sectors are joined against fraud it will develop dicipline among employees. Thus, it needs to be done by decentralized control system inwhich supported SOP to check any evidents related to fraud (Birch,2008). Decentralized is different from deconcentration. Decentralization is the granting authority without ignoring the authority to control over it.

\section{Fraud Avoidances}

In fraud cases, the most vulnerable profession is the profession of accountants and auditors. Enron Corporation financial case raises new spotlight for the accounting profession. One of the supreme leader company Enron had committed suicide after the case opened to public. Survey by Ernst $\&$ Young states found that $15 \%$ of CFOs are willing to "spend" (bribes) to win the business competition or perpetuate the hegemony of the business.

Theoretically, the fraud is done when it meets three criteria: intention, deception, beneficial for private in contrast to stole from others. As I said above, both individually or group, the perpetrator is a man. With so many modes, types, and forms of fraud then the primary unit of analysis is a man, that have associated with self-conciousness, strong political will and law enforcement, and leadership and decentralization to avoid fraud.

Gillian Lees in Fraud Risk Management, A guide to good practice, found more than 110 business enterprises fraud models that start from a trivial thing to the big thing (crucial). Although the pretext has no strict and tiered system with clear procedures could not be ascertained the truth of financial accountability in line with the implementation.

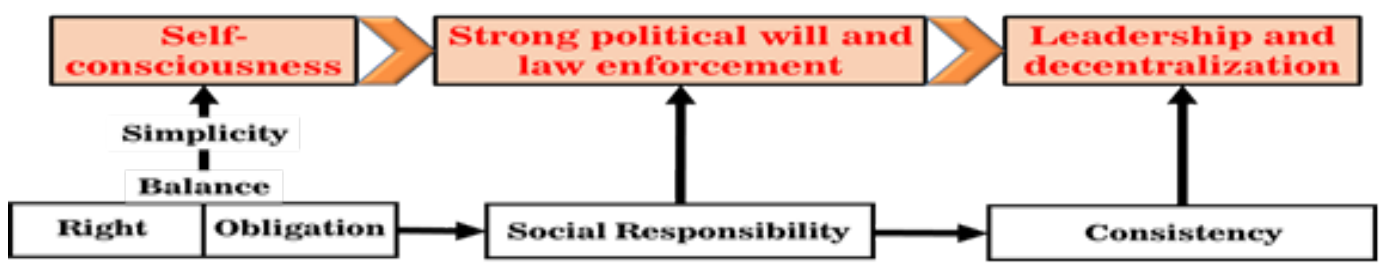

Figure 3. Mechanism of fraud avoidance 
Self-consciousness should be developed among the actors to avoid fraud. Self-awareness is developed not only by power or force, but also by balancing rights and obligation, and balance of reward and punishment. Outstanding employees should be appreciated and rewarded by promotion, extra salary, etc. Those reward will avoid dissatisfaction thereby reducing fraud in the future due to lack of attention from organizations and leaders. Proximity between employees and employess to executives can bind self-awareness and role of each actor.

The balance of right and obligation will be adopted by groups to avoid fraudulent act. Losses are not only experienced by organization but also individual such as case of Citibank Indonesia and the Great Wall Street in the US. Social responsibility will provide fresh air for leadership inside the organization. The fresh air come from government political will and regulations. Regulation must be kept by high integrity of law enforcement officials.
Law enforcement officials maintain regulations to eliminate the quantity and quality of the fraud. Regulation will turn down opportunities the act of fraud. The reasons for an act of fraud cannot be rationalized by the perpetrator because rationalization is actually based on the regulation.

The Indonesian Government has established the Financial Services Authority (FSA) but in reality only focus government bureaucracy at the central and unfair. Structural problems that occur outside of government is very difficult to execute. Even the FSA still requires a lot of personnel to be able to bear the burden and responsibility for so many organizations that are vulnerable to fraud. Thus to have a cadre of integrity begins with a good recruit. When the recruitment process is going well and the government did not make the FSA as an instrument of power, the fraud will be eliminated. All of those efforts can be expalined in the figure 4 below:

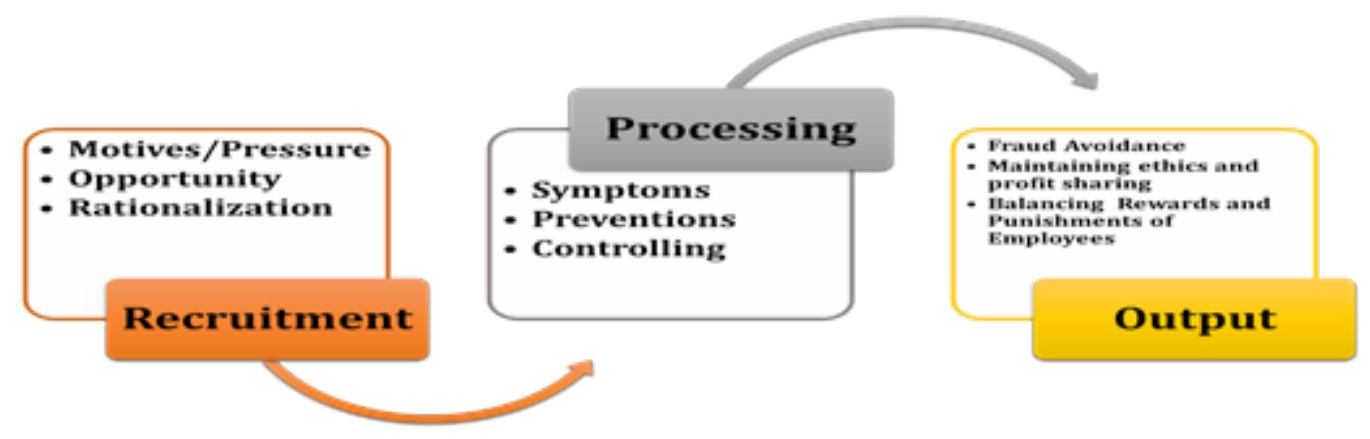

Figure 4. Simple process of fraud avoidance

In the recruitment, the personal character of the employee must be considered such as: can explain the property owned, do not have a lifestyle of luxury, employees often feel disappointed / unsatisfied with the decision of the management, selfish, employees often ignoring the instructions / procedures, and egoistic.

In the processing, fraud ca be detected by knowing symptoms (Red Flags). Red Flags determines by: 1) Personal situation 
of employees, such as debt, ill, education of children, medical problems, etc; 2) Internal situation of organizatin or company such as economy difficulties, debt, unfair competition, etc; 3) Low intention in risk management or lack of internal control system; 4) absolut power; 5) Lack of managerial capabilities; 5) Lack of professional recruitment (DiNapoli, .

GONE is an abreviation to detect fraud. GONE consists of Greed, Opportunity, Need, dan Exposure (Abdullahi and Mansoor,2015). Greed and Need are connected to individual, and Opportunity and Exposure are connected to orgnization or it is called as generic factor. Opportunity can be determined form job or occupation, time, etc that someone by his/ her power conduct fraud. Exposure is related to understanding of environment and witness protections. Greed is related to honesty, integrity, loyalty, etc to avoid fraud. Need is retalte to economy factor, unsatisfacttion, retaliation, etc.

Fraud prevention ican be done by: 1) Using the external auditor; 2) Establish a code of conduct; 3) Authentication on the financial statements; 4) Reviewing the financial management and employees; 5) Develop employee support program; 6) Provide training about fraud avoidance; 7) Provide anti-fraud tips (online, social media, or printing); 8) Incidental internal audit; and 10) To provide a gift for the reporting acts of fraud.

Each company/organization has a vulnerable point of fraud. In detecting fraud can be done in two ways, namely CPA (Critical Point Auditing) and JSA (Job Sensitivity Analysis). Critical
Point Auditing (CPA). CPA is a technique of detection through examination of accounting records to determine a manipulation then investigation in detail and comprehensively will be taken. CPA is done through: trend analysis, ratio analysis, performance, and analysis of special relationship. Specific analysis performed on activities that have a high risk of fraud such as purchasing, verification, sales, marketing, and inventory. Job Sensitivity Analysis (JSA) is based on an assumption when someone / group of employees working in certain positions likely to commit fraud. This method can be taken by preparing an analysis of each official, routine monitoring and followup process.

Good internal controls should include good environmental controls, good accounting systems, and good procedural control. Reflecting on a statement of the Committee of Sponsoring Organizations (COSO) in 2013: "... the control environment sets the tone of the organization, and is largely responsible for employees being conscious (and therefore vigilant) about controls." Environmental controls include integrity, ethics, and competence of human resources (HR), style and management philosophy, management style in the allocation of authority and responsibility, and human resources development, as well as the attention and direction among board of directors. Meanwhile, a good accounting system must provide information that is truthful, complete, and timely. Good procedural control should include physical control over assets, appropriate authorization, segregation 
of duties, independent checks, and complete documentation.

It should be noted, there is no internal control system that is immune to fraud. Effectiveness will depend on the competence of supervisors or auditors who must ensure the implementation of internal controls. Internal control system is just one element of a comprehensive fraud prevention program. For example the prevention program of data by upgrading antivirus, maintenance of computer system and applications, encryptions, etc.

Companies protections can be achieved through reconciliation of bank accounts periodically, careful evaluation and approval of all cashout transaction, placing more than one person to control the accounts, dedicates a specific computer to online banking, develop a fraud prevention education for employees. Steps that can be taken by the company to ensure they are completely safe from is to ensure the company/ organization has the Internal Control System.

In conditions of low integrity, weak controls, low accountability, and high pressure, chances of someone being dishonest will be higher. The condition is currently faced with two simple choices: to create low fraud environment or following the breakdown of the organization or companies in the past. Low fraud environment can be developed by culture which has high integrity, openness can be achieved by understanable code of conduct.

Based on fraud triangle, then the pressure, opportunity, and rationalization that come together will increase the chances of fraud. But, if any one of the triangular elements is missing, fraud will not occur. Build obstacle to collusion because fraud occurs accompanied by collusion. Collusion is usually not built in a short time so the sollution is to rotate personnel or job transfer periodically. The companies or organization provide clear policy and information to customers periodically about avoidance of any bribes or gifts. Suspected perpetrators can be determined by changing in life style and private facilities. Therefor, companies or organizations should make a hotline. When a personnel felt that co-workers or others have a very easy way to report the occurrence of fraud, it will reduce the intention of doing fraud itself. Usualy an investigation of fraud carried out after the victims found (reactive). Proactive means to build awareness of the personnel that what they are doing at any moment be reviewed. This will provide the personality fear to be caught if doing fraud. Fear of punishment will obviously reduce dishonest behavior. Punishment firm and consistent will make people think a thousand times before ensuring ready to commit fraud. If it were just fired, sometimes not strong enough to prevent fraud. Thus, people can tell the family or those closest to the dishonest behavior of the personnel who do fraud as social punishment. The company that wants to protect its assets should have clear policy about the nature and magnitude of sanctions against perpetrators of fraud, such as: anyone involved fraud can be dismissed or legal sanctions. This research uses a qualitative research design. Analyses were performed by literature review. 


\section{Conclusion.}

In sum, fraud is expected to be reduced and prevented by creating a culture of honesty, openness, support programs for employees, and efforts to eliminate the chance of the personnel to commit fraud. Creating a good internal control is one of the steps that can be taken to prevent fraud. We all hope, fraud is least subside. Fraud may not be removed to zero, but can be reduced with real action and synergy between the strong political will of government in line with the company / organization. No party won in case of fraud, because the company / organization losers and players only feel the thrill a while.

Author: Dr. Safril Hidayat, psc, M.sc. Doctor in International Relation Science. He can be contacted through safrilhidayatzeni1995@ yahoo.co.id. Phone : 08221886 9595, 0812 82821309 (WA and Telegram). Paper for ACFE,Socio-political, Political science.

\section{References:}

Abdullahi, Rabi'u and Mansor, Noorhayati. (2015). Fraud Triangle Theory and Fraud Diamond Theory. Understanding the Convergent and Divergent For Future Research. In International Journal of Academic Research in Accounting, Finance and Management Sciences Vol. 5, No.4, October 2015, pp. 38-45. Source: http://hrmars.com/hrmars_ papers/Article_05_Fraud_Triangle_ Theory_and_Fraud_Diamond_Theory. pdf. Downloaded on 28 July 2016, 19.30.

Adrews, Matthew. (2004). Authority, Acceptance, Ability, and Performance-
Based Budgeting Reforms. International Journal of Public Sector Management. 17 (4):332-44.

(2007). Governance Reform under Real World Conditions: A Dialogue on Communication Challenges. Washington DC: CommGap. Source: http://siteresources.worldbank. org / EX T GOVA C C/Res ources / Governance\&CommDialogue_Final_. pdf. Downloaded on 30 July 2016, 20.44.

Bardhan, Pranab and Mookherjee, Dilip. (2000). Capture and Governance at Local and National Levels. American Economic Review Vol. 90, No.2, 135-139.

Birch, Martin et al. (2008). Fraud Risk Management. A Guide to Practice. UK: CIMA.

Committee of Sponsoring Organizations of the Treadway Commission (COSO). (2013). The Updated COSO Internal Control Framework. Frequently Asked Question. Second Edition. Source: https://www.protiviti.com/en-US/ Documents/Resource-Guides/UpdatedCOSO-Internal-Control-FrameworkFAQs-Second-Edition-Protiviti.pdf. Downloaded on 30 July 2016, 20.41.

David Hume. (1739). A Treatise of Human Nature. Reprinted from the Original Edition in three volumes and edited, with an analytical index, by L.A. SelbyBigge. (1896). Oxford: Clarendon Press. 
James, W. (1961). Psychology: The Briefer Course. Edited by G. Allport. New York: Harper and Row.

Joseph Chianese et al. (2012). Red Flags of Fraud. UK: Deloitte Development LLC.

Odugbemi, Sina and Jacobson, Thomas. (2008). Governance Under RealWorld Conditions Reform. Citizens, Stakeholders, and Voice. Washington DC: World Bank.

Prud'homme, R. 1994. On the Dangers of Decentralization. Policy Research Working Paper Series. No. 1252. Washington, DC: World Bank.

Reinikka, Ritva and Svensson, Jakob. (2004). Fighting Corruption to Improve Schooling: Evidence From A Newspaper Campaign in Uganda. Source: http:// econ.1se.ac.uk/staff/rburgess/eea/ svenssonjeea.pdf. Downloaded on 30 July 2016, 20.30.

Shah, Anwar. (2008). Fiscal Decentralization and Macroeconomic Governance. Washington, DC: World Bank. Source: http://www.cepal.org/ilpes/noticias/ paginas/1/32221/Anwar_Shah_Fiscal_ Dec_and_Macromanagement.pdf. Downloaded on 29 July 2016, 20.30.

Tanzi, Vito. (1995). Fiscal Federalism and Decentralization. A Review of Some Efficiency and Macroeconomics Aspects. Source: https://www.mef.gob. pe/contenidos/pol_econ/documentos/ Fiscal_Federalism_Decentralization.pdf. Downloaded on 30 July 2016, 11.41.
Tanzi, Vito. (1995). Taxation in an Integrating World. Washington, DC: Brookings Institution Press

Thomas P. DiNapoli. Red Flags for Fraud. New York: Source: https://www.osc.state. ny.us/localgov/pubs/red_flags_fraud.pdf. Downloaded on 29 July 2016, 20.50.

Indonesia-Investment. (2016). Banking Sector Indonesia: OJK Needs More People to Combat Fraud. Source: Http://www. indonesia-investments.com/id/finance/ financial-columns/banking-sectorindonesia-ojk-needs-more-people-tocombat-fraud/item6351. Downloaded on 5 July 2016, 14.03.

James, Geoffrey. (2011). Top 14 Financial Frauds of All Time. Source: Http://www. cbsnews.com/media/top-14-financialfrauds-of-all-time, dowloaded on 5 July 2016. 13.07. 
Safril Hidayat : Strong leadership and political will in fraud avoidance .....

Page 81-92 